\title{
QUANTIFICATION OF LACTOBACILLUS HELVETICUS IN A MIXTURE OF LACTIC ACID BACTERIA USING qPCR IN CHEESE
}

\author{
A. Mühlhansováa $A^{a}$ N. ZheXenbay , A. Kozybayev ${ }^{b}$, Š. HoráčKovÁa \\ and M. Plockovía

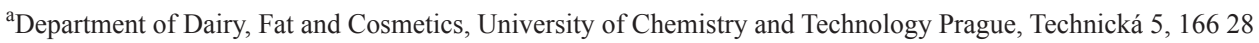 \\ Prague. Czech Republic \\ ${ }^{\mathrm{b}}$ Almaty Technological University, Tole bi street 100, 050012, Almaty. Kazachstan
}

(Received: 13 January 2016; accepted: 29 February 2016)

\begin{abstract}
Conventional quantification of $L$. helveticus, in presence of other lactobacilli species, using classical plate method employing low selective media is very inaccurate. Determination of L. helveticus using quantitative PCR (qPCR) was performed in six artisanal Kazakh soft cheeses made from cow's milk or from a mixture of cow's and goat's milk. L. helveticus was quantified by species-specific qPCR, monitoring the presence of genes encoding for peptidoglycan hydrolases. Quantification of $L$. helveticus based on qPCR ranged from $2.6 \times 10^{6}$ to $4.1 \times 10^{8} \mathrm{CFU} \cdot \mathrm{g}^{-1}$ according to the type of the cheese. The microflora of cheese consisted of a mixture of starter and non-starter lactic acid bacteria.
\end{abstract}

Keywords: L. helveticus, cheese, qPCR, peptidoglycan hydrolases

National Kazakh cheese is an acid-rennet curd cheese ripened over a short period of time containing L. helveticus, a thermophilic lactic acid bacterium used traditionally for production of Gruyère, Emmental, Grana, and Parmesan cheeses (BERESFord et al., 2001). This variety was first produced with a mixture of goat's milk, and currently is made from cow's milk. L. helveticus can be determined using culture-dependent or culture-independent methods. Culture-dependant methods are generally labour intensive, time consuming, and more or less specific of a microbial group (ACHIELlos \& BERTHIERE, 2013). Only strains able to grow under the defined environmental conditions can be monitored, apart from viable but non-cultivable cells. Moreover, L. helveticus occurs in cheese in the presence of other lactobacilli; therefore, its quantification using classical plating method is difficult (ForTINA et al., 2001). In a food matrix, such as cheese, culture-independent methods have rapidly been recognized as valuable alternatives to culture-dependant methods. These methods are based on the direct analysis of DNA extracted from the cheese matrix with no enrichment steps. Among cultureindependent methods, qPCR represents a powerful tool for the quantification of microbial populations through the determination of targeted gene copies (Achiellos \& Berthiere, 2013). Both dead and viable cells can be detected by qPCR (GARCIA-CAYULE et al., 2009). The design and use of specific primers has been proven to be a valuable tool for quantifying bacteria in cheeses like Emmental (FALENTIN et al., 2010, 2012), fresh cheese (FURET et al., 2004), and other cheese-types (LADERo et al., 2008, 2010). The qPCR has been used for quantification of technologically important bacteria such as Lactococcus lactis, Lactobacillus rhamnosus, Brevibacterium linens, Lactobacillus fermentum, Streptococcus thermophilus,

\footnotetext{
* To whom correspondence should be addressed

Phone: +420 22044 3831; fax: +420 22044 3285; e-mail: katerina.solichova@vscht.cz
} 
Lactobacillus delbrueckii, Lactobacillus casei, Lactobacillus paracasei, or Lactobacillus acidophilus (Achiellos \& Berthiere, 2013). Many studies showed that L. helveticus has technological importance, especially regarding probiotic activity and bioactive peptides production by certain strains (SADAT-MEKMENE et al., 2011). To our knowledge, a simple PCR method to quantify L. helveticus in a mixture of lactic acid bacteria in cheese has not been reported yet. Therefore, the aim of this work was to quantify L. helveticus in soft cheeses produced in Kazakhstan by a species specific qPCR method in a mixture of starter and nonstarter cultures.

\section{Materials and methods}

\subsection{Cheese manufacture}

Six cheese samples were manufactured in a dairy pilot plant in Kazakhstan. Three cheeses were produced from cow's milk and three cheeses were the new samples of Kazakh national soft cheese (irimshik). They were made from a mixture of goat's and cow's milk with the addition of skimmed cow's milk up to $15 \%$ mass fraction of dry matter in the milk. Milk for cheese production was treated with a low pasteurization $\left(72 \pm 2{ }^{\circ} \mathrm{C}, 15-20 \mathrm{~s}\right)$. Christian Hansen FD-DVS DCC-260 was used as starter culture and contained these lactic acid bacteria: Lactococcus lactis subsp. cremoris, Lactococcus lactis subsp. lactis, Leuconostoc mesenteroides subsp. cremoris, Lactococcus lactis subsp. diacetylactis, Lactobacillus casei, Lactobacillus helveticus, and Streptococcus thermophilus.

Two different cheese types were made following the traditional technology in three different moments to obtain the 7, 14, and 21 day-old cheeses: CCM (cheese made from cow's milk), and CGCM (cheese made from goat's milk and cow's milk, 1:1 ratio). The 7, 14, and 21 day-old cheeses were analysed at the same time. The $\mathrm{pH}$ was determined by using a pH-meter (expert-001, Russia).

\subsection{Determination of bacterial composition}

Serial dilutions of cheese were prepared in sterile $1 \%(\mathrm{w} / \mathrm{v})$ peptone solution and plated on MRS agar medium (pH 5.4) for the determination of Lactobacillus spp., M17 agar medium for the determination of Lactococcus spp. and Streptococcus thermophilus, agar medium according to NicKels and LEESMENT (1964) for the determination of citrate-fermenting bacteria (ISO, 2006), and agar medium according to NicKels and LeESMENT (1964) with vancomycin supplementation for the determination of Leuconostoc spp. (ISO, 2006). Plates with MRS agar medium (pH 5.4) were incubated anaerobically at $37^{\circ} \mathrm{C}$ for $72 \mathrm{~h}$. Plates with M17 agar medium were incubated aerobically at $37^{\circ} \mathrm{C}$ for $48 \mathrm{~h}$. Plates with medium according to NiCKels and LEESMENT (1964) with and without vancomycin were incubated aerobically at $25^{\circ} \mathrm{C}$ for 5 days. Pure cultures of L. helveticus DPC 4571 were determined on MRS agar (pH 5.4) and incubated at $37^{\circ} \mathrm{C}$ for $48 \mathrm{~h}$.

\subsection{PCR amplification}

DNA was isolated from pure cultures and cheeses as published by PARAYRE and co-workers (2007). This method uses combination of mechanical and enzymatic lysis. DNA concentration was determined by using Nanodrop ND-1000 (NanoDrop Technologies, USA). L. helveticus DPC 4571, L. acidophilus LA5, L. casei L26, and L. rhamnosus CCM1825 were cultured in 
culture tubes with MRS broth (pH 5.4). Total DNA from cell culture was extracted by using DNeasy Blood \& Tissue kit (Qiagen, Germany) as described in the manufacturer's instructions. All DNA samples were frozen before analyses.

Real-time PCR amplification and analysis were performed using Real-time PCR cycler CFX-96 (Bio-Rad, USA) with species-specific primers for L. helveticus for Lhv_0190 gene (Fwd: CAGTTGTGTTGACTTCCACAAT, Re: CAAATTGTGGCTGGTGATTCT) and Lhv_0191 gene (Fwd: GGGCTGATTACAGTGGCTAAT, Re: CTTGCCCTTTTCGGTGTAAA). The selected primers are highly selective and are able to discriminate accurately $L$. helveticus from other closely related homofermentative lactobacilli, especially L. gallinarum, L. acidophilus, and L. delbruckeii (JeBAvA et al., 2014). The initial composition of the PCR reaction mix was as follows: $2 \mu$ genomic DNA, $10 \mu \mathrm{l}$ iQSybr Green Supermix (BioRad), $7 \mu$ demineralised sterile water, $1 \mu$ of each primer $(50 \mu \mathrm{M})$ in a final volume of $20 \mu \mathrm{l}$. The PCR conditions were: initial denaturation step at $95^{\circ} \mathrm{C}$ for $5 \mathrm{~min}$, followed by 30 cycles of amplification (denaturation at $95^{\circ} \mathrm{C}$ for $30 \mathrm{~s}$, annealing at $64^{\circ} \mathrm{C}$ for $30 \mathrm{~s}$, and extension at $72{ }^{\circ} \mathrm{C}$ for $45 \mathrm{~s}$ ).

The PCR conditions and composition of the PCR reaction were the same for pure culture of $L$. helveticus DPC 4571 (described above) as well as for negative control strains ( $L$. acidophilus LA5, L. casei L26, L. rhamnosus CCM1825). Non-template control was included in all PCR assays. Purification of the PCR product was carried out using commercially available QIAquick PCR Purification Kit (Qiagen, Germany) as described in the manufacturer's instructions. The concentration of the purified PCR product was measured by spectrophotometry using Nanodrop ND-1000 and the corresponding copy number was calculated using the following equation (LEE et al., 2006).

$$
\operatorname{DNA}(\text { copy })=\frac{6.02 \times 10^{23}(\text { copy } / \mathrm{mol}) \times \text { DNAamount }(\mathrm{g})}{\text { DNAlenght }(\mathrm{dp}) \times 660(\mathrm{~g} / \mathrm{mol} / \mathrm{dp})}
$$

Decimal dilutions for the calibration curve were prepared according to a calculation of the copy number of DNA. Two calibration curves were prepared using two sets of primers (Lhv_0190,_Lhv_0191). The same method for absolute quantification using qPCR as describe above was used to quantify counts of $L$. helveticus in pure cultures and in cheeses.

\section{Results and discussion}

\subsection{Cheese manufacture and determination of bacterial composition}

Characteristics of six Kazakh cheeses and results for culture-dependent plating methods used for the identification and quantification of microorganisms in cheeses are presented in Table 1. No significant differences in counts of bacteria were detected, and they ranged from $10^{8}$ to $10^{9} \mathrm{CFU} \mathrm{g}^{-1}$. Only cheese $\mathrm{N}^{\circ} 6$ showed lower numbers of citrate fermenting bacteria $\left(10^{6} \mathrm{CFU} \mathrm{g}{ }^{-1}\right)$. The most important mesophilic lactic acid bacteria that ferment citrate belong to Lactococcus lactis subsp. lactis biovar. diacetylactis and Leuconostoc mesenteroides subsp. cremoris. Diagnostic characteristics of lactococci and leuconostoc were distinguishable by this method (ISO, 2006). Leuconostoc colonies are blue; lactococcus colonies are white with a zone of clearing. Present knowledge of microbial diversity and dynamics in cheese is mainly based on culture-dependent methods, involving traditional numeration followed by 
identification of dominant microorganisms using phenotypic and molecular methods (FALENTin et al., 2012). Cheese contains a complex combination of microorganisms that changes with time; initially containing large numbers of starter lactic acid bacteria and then with maturation, an increasing number of non-starter lactic acid bacteria (KARIMI et al., 2012).

Table. 1. Cheese characterization, bacterial counts by plating method and quantification of $L$. helveticus using qPCR method with two primer sets

\begin{tabular}{|c|c|c|c|c|}
\hline Sample & Used milk & $\begin{array}{l}\text { Period of ripening } \\
\text { (day) }\end{array}$ & \multicolumn{2}{|c|}{$\mathrm{pH}$} \\
\hline Cheese 1 & $\mathrm{CGCM}^{\mathrm{a}}$ & 7 & \multicolumn{2}{|c|}{5.06} \\
\hline Cheese 2 & $\mathrm{CGCM}^{\mathrm{a}}$ & 14 & \multicolumn{2}{|c|}{4.91} \\
\hline Cheese 3 & $\mathrm{CGCM}^{\mathrm{a}}$ & 21 & \multicolumn{2}{|c|}{4.95} \\
\hline Cheese 4 & $\mathrm{CCM}^{\mathrm{b}}$ & 7 & \multicolumn{2}{|c|}{4.86} \\
\hline Cheese 5 & $\mathrm{CCM}^{\mathrm{b}}$ & 14 & \multicolumn{2}{|c|}{4.67} \\
\hline \multirow[t]{3}{*}{ Cheese 6} & $\mathrm{CCM}^{\mathrm{b}}$ & 21 & & \\
\hline & \multicolumn{4}{|c|}{ Bacterial counts $\left[\mathrm{CFU} \cdot \mathrm{g}^{-1}\right]$} \\
\hline & $\begin{array}{l}\text { Lactococcus spp., } \\
\text { St. thermophilus }\end{array}$ & $\begin{array}{c}\text { citrate-fermenting } \\
\text { bacteria }\end{array}$ & Leuconostoc spp. & Lactobacillus spp. \\
\hline Cheese 1 & $2.4 \cdot 10^{9}$ & $3.4 \cdot 10^{8}$ & $2.5 \cdot 10^{8}$ & $1.0 \cdot 10^{9}$ \\
\hline Cheese 2 & $2.8 \cdot 10^{9}$ & $2.0 \cdot 10^{8}$ & $1.5 \cdot 10^{8}$ & $1.9 \cdot 10^{9}$ \\
\hline Cheese 3 & $1.2 \cdot 10^{9}$ & $1.8 \cdot 10^{9}$ & $1.7 \cdot 10^{8}$ & $9.8 \cdot 10^{8}$ \\
\hline Cheese 4 & $1.8 \cdot 10^{9}$ & $2.5 \cdot 10^{8}$ & $1.7 \cdot 10^{8}$ & $9.4 \cdot 10^{9}$ \\
\hline Cheese 5 & $2.1 \cdot 10^{9}$ & $1.7 \cdot 10^{8}$ & $1.7 \cdot 10^{8}$ & $7.6 \cdot 10^{8}$ \\
\hline \multirow[t]{3}{*}{ Cheese 6} & $1.4 \cdot 10^{9}$ & $5.0 \cdot 10^{6}$ & $3.6 \cdot 10^{8}$ & $6.3 \cdot 10^{8}$ \\
\hline & \multicolumn{4}{|c|}{ Number of $L$. helveticus cells $\left[\mathrm{CFU} \cdot \mathrm{g}^{-1}\right]$} \\
\hline & \multicolumn{2}{|c|}{ Lhv_0190 } & \multicolumn{2}{|c|}{ Lhv_0191 } \\
\hline Cheese 1 & \multicolumn{2}{|c|}{$3.7 \cdot 10^{7} \pm 6.9 \cdot 10^{3}$} & \multicolumn{2}{|c|}{$8.9 \cdot 10^{7} \pm 4.1 \cdot 10^{3}$} \\
\hline Cheese 2 & \multicolumn{2}{|c|}{$4.3 \cdot 10^{7} \pm 4.7 \cdot 10^{3}$} & \multicolumn{2}{|c|}{$1.0 \cdot 10^{8} \pm 7.1 \cdot 10^{3}$} \\
\hline Cheese 3 & \multicolumn{2}{|c|}{$2.5 \cdot 10^{8} \pm 4.2 \cdot 10^{4}$} & \multicolumn{2}{|c|}{$4.1 \cdot 10^{8} \pm 4.6 \cdot 10^{3}$} \\
\hline Cheese 4 & \multicolumn{2}{|c|}{$3.9 \cdot 10^{6} \pm 5.9 \cdot 10^{2}$} & \multicolumn{2}{|c|}{$1.0 \cdot 10^{7} \pm 3.3 \cdot 10^{4}$} \\
\hline Cheese 5 & \multicolumn{2}{|c|}{$4.8 \cdot 10^{7} \pm 6.3 \cdot 10^{3}$} & \multicolumn{2}{|c|}{$1.2 \cdot 10^{8} \pm 3.4 \cdot 10^{3}$} \\
\hline Cheese 6 & \multicolumn{2}{|c|}{$2.6 \cdot 10^{6} \pm 1.1 \cdot 10^{2}$} & \multicolumn{2}{|c|}{$6.5 \cdot 10^{6} \pm 3.6 \cdot 10^{2}$} \\
\hline
\end{tabular}

${ }^{\mathrm{a}} \mathrm{CGCM}$ (cheese made from goat's milk and cow's milk, 1:1 ratio), ${ }^{\mathrm{b}} \mathrm{CCM}$ (cheese made from cow's milk)

Because of the presence of other lactobacilli closely related to L. helveticus in the culture, and the deficiency in a reliable species selective agar medium, it was impossible to determine selectively $L$. helveticus using plating method based on MRS agar. Thus, total counts of lactobacilli were determined. Most plating methods are based on pure cultures of these organisms and fail to work in products because of the presence of multiple and closely related species making the differential or selective enumeration of probiotic and starter bacteria difficult due to similarity in growth requirements and overlapping biochemical characteristics of the species (ASHRAF \& SHAH, 2011).

Acta Alimentaria 45, 2016 


\section{2. $q P C R$ determination}

First the absolute quantification method was verified in pure cultures of $L$. helveticus DPC 4571 in comparison with the plate count method. The results were as follows: plate count on MRS (pH 5.4) agar $8.5 \cdot 10^{7} \pm 2.1 \cdot 10^{1} \mathrm{CFU} \cdot \mathrm{ml}^{-1}$, qPCR with Lhv_0190 9.2 $10^{7} \pm 1.2 \cdot 10^{2}$ CFU $\cdot \mathrm{ml}^{-1}, \mathrm{qPCR}$ with Lhv_0191 $1.1 \cdot 10^{8} \pm 3.1 \cdot 10^{2} \mathrm{CFU} \cdot \mathrm{ml}^{-1}$. These results are averages of 10 assessments and do not differ substantially, and thus the suitability of chosen qPCR method is confirmed.

The soft cheese irimshik was selected for the first trial, because DNA isolation from this soft cheese was unambitious and defined starter culture was used for its production. The DNA concentration (quantified by Nanodrop ND-1000) extracted from 6 different cheeses varied from 4.7 to $56.7 \mu \mathrm{g} \cdot \mathrm{g}^{-1}$ cheese. The DNA concentration was in agreement with previously published data quantifying DNA extracted from cheese matrix (JACQUIN et al., 2001; LEE et al., 2006), reporting concentrations of DNA extracted from 10 different dairy products between 0.7 to $29.2 \mu \mathrm{g} \cdot \mathrm{g}^{-1}$ using picogreen spectrofluorimetry, respectively, 4 to 19 $\mu \mathrm{g}$ DNA $\cdot \mathrm{g}^{-1}$ of Emmental cheese using spectrophotometric method.

A

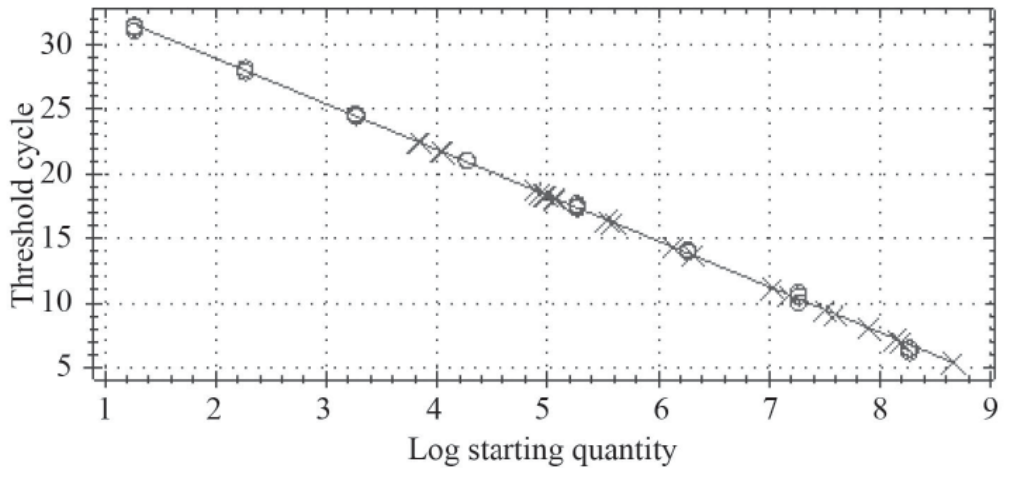

B

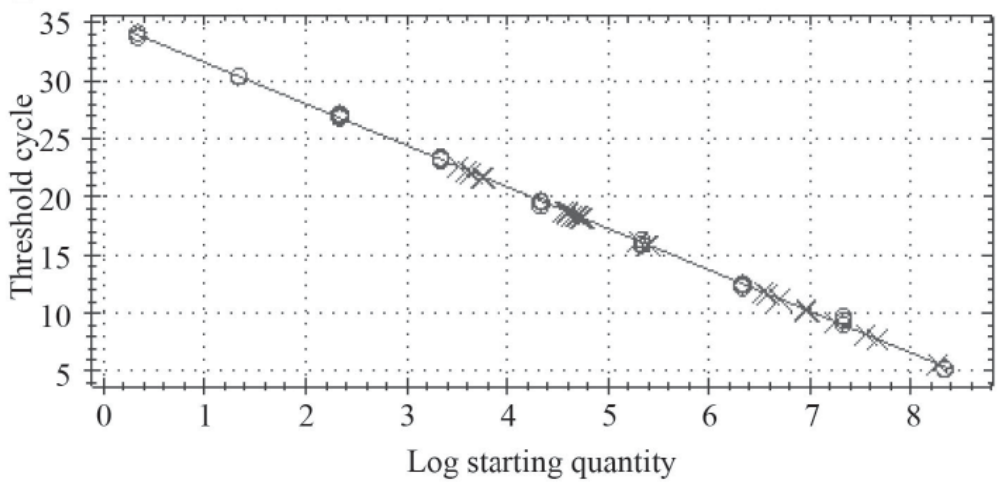

Fig. 1. Calibration curves for A: Lhv 0190 and B: Lhv 0191 from qPCR assay o: standard - L. helveticus DPC 4571; X: unknown samples (cheeses)

-: SYBR (A: efficiency $91.9 \%$, slope -3.53 ; B: efficiency $90.6 \%$, slope -3.57 ) 
Two qPCR assays targeting peptidoglycan hydrolases were developed for the absolute quantification of L. helveticus in food matrices. One pair of primers Lhv_0190 encoding $\mathrm{N}$-acetylmuramidase and the other one Lhv_0191 encoding amidase. Two pairs of primers were used to observe possible differences. Ascertained differences between obtained results for these two pairs of primers were minimal and error is within the standard deviation. Quantification of $L$. helveticus using qPCR ranged from $2.6 \cdot 10^{6}$ to $4.1 \cdot 10^{8} \mathrm{CFU} \cdot \mathrm{g}^{-1}$, and particular results are shown in Table 1. The standard curves for Lhv_0190 and Lhv_0191 were linear in the range tested $\left(\mathrm{R}^{2}>0.999\right)$ by the triplicate reactions (Fig. 1).

Amplification was linear over the range of $1.8 \cdot 10^{1}$ to $1.8 \cdot 108$ for Lhv_0190 and $2.1 \cdot 10^{\circ}$ to 2.1 108 for Lhv_0191, respectively, of DNA copies. The slope of the standard curves for Lhv_0190 and Lhv_0191 were -3.53 and -3.57 , respectively. Quantitation cycle (Cq) for positive control was 16.2 for Lhv_0190 and 15.1 for Lhv_0191, respectively, Cq for all three negative controls were above 34 for both primer sets, Cq for NTC was $>35$. Efficiencies of qPCR were 91.9\% for Lhv_0190 and 90.6\% for Lhv_0191, respectively. Intra-assay CV was $2.3 \%$ for Lhv 0190 and $0.9 \%$ for Lhv 0191 .

Because both $L$. helveticus and $\bar{L}$. casei were present in the used starter culture and cheese contains probably other lactobacilli of non-starter origin as well, the determination of L. helveticus was difficult using non-selective MRS ( $\mathrm{pH} 5.4$ ) agar. It was not possible to compare the results of plating methods to qPCR. Direct qPCR quantification has proven to be useful, providing additional information to plate counts. In addition, the use of speciesspecific primer pairs at the given PCR conditions proved to be a very rapid and effective method for quantification of the species. Our results confirmed the necessity of using the species-specific qPCR for the determination and quantification of lactobacilli in mixtures.

When we critically assess both the pros and cons of qPCR, we have to say that usage of qPCR for quantification of $L$. helveticus is an alternative to plating methods. More particularly, qPCR is considered as the first choice method, and its major advantage is that it is less-time consuming than conventional culture based methods. It is also highly sensitive, specific, enables simultaneous detection of different microorganisms, and requires no post-processing (MARtinÉz et at., 2011; Postollec et al., 2011). Method of qPCR has also some limitations, for example the precision of molecular quantification by PCR depends on the effectiveness of bacterial lysis of DNA extraction, and on the presence of PCR inhibitors in the DNA solution (FURET et al., 2004). Reliable quantification depends on optimized and carefully performed qPCR reactions. The accuracy of qPCR is influenced by primer design, the quality of the template DNA, and the handling and storage of samples, primers, and enzymes. With food samples, special attention must be paid to the possible presence of inhibitors and to the efficiency of DNA extraction. Provided appropriate control (e.g. positive PCR control, nontemplate control, control for environmental contamination, etc.) are included in the analyses, proposed qPCR appears to be highly accurate and reliable for quantification of targeted genes (Postollec et al., 2011).

\section{Conclusions}

In conclusion, our results suggest that application of simple, fast, and accurate qPCR method is eligible for species specific quantification of L. helveticus in cheese matrix containing other lactic acid bacteria including lactobacilli. In this work soft cheese was used as matrix. Other experiments with different cheeses and other dairy products will follow in the very near future to verify appropriateness of this method and its independence of food matrix and composition of microflora. 
This work was financially supported by specific university research (Ministry of Education, Youth and Sports, The Czech Republic, No. 20/2014).

\section{References}

Achiellos, C. \& Berthiere, F. (2013): Quantitative PCR for the specific quantification of Lactococcus lactis and Lactobacillus paracasei and its interest for Lactococcus lactis in cheese samples. Food Microbiol., 36, 286295.

Ashraf, R. \& Shah, N. (2011): Selective and differential enumerations of Lactobacillus delbrueckii subsp. bulgaricus, Streptococcus thermophilus, Lactobacillus acidophilus, Lactobacillus casei and Bifidobacterium spp. in yoghurt - A review. Int. J. Food Microbiol., 149, 194-208.

Beresford, T., Fitzmol, N., Brennan, N. \& Cogan, T. (2001): Recent advances in cheese microbiology. Int. Dairy J., 11, 259-274.

Falentin, H., Postollec, F., Parayre, S., Henaff, N., Le Bivic, P., Richoux, R., Thierry, A. \& Sohier, D. (2010): Specific metabolic activity of ripening bacteria quantified by real-time reverse transcription PCR throughout Emmental cheese manufacture. Int. J. Food Microbiol., 144, 10-19.

Falentin, F., Henaff, N., Le Bivic, P., Deutsch, S.M., Parayre, S., Richoux, R., Sohier, D., Thierry, A., Lortal, S. \& Postollec, F. (2012): Reverse transcription quantitative PCR revealed persistency of thermophilic lactic acid bacteria metabolic activity until the end of the ripening of Emmental cheese. Food Microbiol., 29, 132140.

Fortina, M.G., Ricci, G., Mora, D., Parini, C. \& Manachini, P.L. (2001): Specific identification of Lactobacillus helveticus by PCR with pepC, pepN and htrAtarger primers. FEMS Microbiol. Lett., 198, 85-89.

Furet, J.P., QuÉnÉE, P. \& TAilliez, P. (2004): Molecular quantification of lactic acid bacteria in fermented milk products using real-time quantitative PCR. Int. J. Food Microbiol., 97, 197-207.

Garcia-Cayule, T., Tabasco, R., Pelaey, C. \& Requena, T. (2009): Simultaneous detection and enumeration of viable lactic acid bacteria and bifidobacteria in fermented milk by using propidium monoazide and real-time PCR. Int. Dairy J., 19, 405-409.

ISO (2006): Milk, milk products and mesophilic starter cultures - Enumeration of citrate-fermenting lactic acid bacteria - Colony-count technique at 25 degrees C. ISO 17792, IDF, 2006, pp. 1-12.

JACQuin, J., Aragno, M. \& Rossi, P. (2001): Application of the bead beater technique to the extraction of bacterial DNA from cheese samples. Milchwissenschaft, 56, 563-565.

Jebava, I., Chuat, V., Lortal, S. \& Valence, F. (2014): Peptidoglycan hydrolases as species-specific markers to differentiate Lactobacillus helveticus from Lactobacillus gallinarum and other closely related homofermentative lactobacilli. Curr. Microbiol., 68, 551-557.

Karimi, R., Mortayavian, A. \& Amiri-Rigi, A. (2012): Selective enumeration of probiotic microorganisms in cheese. Food Microbiol., 29, 1-9.

Ladero, V., Linarez, D., Fernández, M. \& Alvarez, M. (2008): Real time quantitative PCR detection of histamineproducing lactic acid bacteria in cheese: Relation with histamine content. Food Res. Int., 41, 1015-1019.

Ladero, V., Fernández, M., Cuesta, I. \& Alvarez, M. (2010): Quantitative detection and identification of tyramineproducing enterococci and lactobacilli in cheese by multiplex qPCR. Food Microbiol., 27, 933-939.

LeE, C., KIm, J., Shin, S. \& Hwang, S. (2006): Absolute and relative QPCR quantification of plasmid copy number in Escherichia coli. J. Biotechnol., 123, 273-280.

Martinéz, N., Martin, M.C., Herrero, A., Fernández, M., Alvarez, M.A. \& Ladero, V. (2011): qPCR as a powerful tool for microbial food spoilage quantification: Significance for food quality. Trends Food Sci. Tech., 22, $367-376$

Nickels, C. \& Leesment, H. (1964): Methode zur Differenzierung und quantitative Bestimmung von Säureweckerbakterien. Milchwissenschaft, 19, 374-378.

Parayre, S., Falentin, H., Madec, M.N., Sivieri, K., Le Dizes, A.S., Sohier, D. \& Lortal, S. (2007): Easy DNA extraction method and optimization of PCR-Temporal Temperature Gel Electrophoresis to identify the predominant high and low GC-content bacteria from dairy products. J. Microbiol. Meth., 69, 431-441.

Postollec, F., Falentin, H., Pavan, S., Combrisson, J. \& Sohier, D. (2011): Recent advances in quantitative PCR (qPCR) applications in food microbiology. Food Microbiol., 28, 848-861.

Sadat-Mekmene, L.,Genay, M., Atland, D., Lortal, S. \& Gagnaire, V. (2011): Original features of cell-envelope proteinases of Lactobacillus helveticus. A review. Int. J. Food Microbiol., 146, 1-13. 